three preparations up to six months after treatment, only their potential value in mass treatment may be estimated as follow up for one year is a minimum requirement. For the individual subject infected with $S$ haematobium praziquantel is the most effective and convenient drug available. If, however, cost is an important factor and parasitological cure not an essential objective the combined regimen in a single dose is a valid alternative in an endemic area.

We thank Dr R H Ellison, Nairobi, for the double blind method and assistance with analysis; Dr D R Bell, Liverpool, and Dr A Davis, Geneva, for their comments; Dr D H G Wegner, Leverkusen, for the supply of praziquantel; A J Kapeta, G H Manjolo, F P Nanzeze, B K Chirombo, and P K Chirwa for field assistance; and T A Maere and G H C Phiri for performing the microscopy. This study was made possible through the support of the Overseas Development Administration, UK, and the Ministry of Health, Malawi.

\section{References}

${ }^{1}$ Davis A, Biles JE, Ulrich A-M. Initial experiences with praziquantel in the treatment of human infections due to Schistosoma haematobium. Bull WHO 1979;57:773-9.

${ }^{2}$ Katz N, Rocha RS, Chaves A. Preliminary trials with praziquantel in human infections due to Schistosoma mansoni. Bull WHO 1979;57: $781-5$.

${ }^{3}$ Santes AT, Blas BL, Nosenas JS, et al. Preliminary clinical trials with praziquantel in Schistosoma japonicum infections in the Philippines. Bull WHO 1979;57:793-9.
${ }^{4}$ Anonymous. Praziquantel: a new hope for schistosomiasis (Editorial). Lancet 1980; ; $635-6$.

${ }^{5}$ Siongok TKA, Ouma JH, Houser HB, Warren KS. Quantification of infection with Schistosoma haematobium in relation to epidemiology and selective population chemotherapy. II Mass treatment with a single oral dose of metriphonate. F Infect Dis 1978;38:856-8.

${ }^{6}$ Pugh RNH. Malumfashi endemic diseases research project. V Concurrent single dose metrifonate and niridazole in urinary schistosomiasis. Ann Trop Med Parasitol 1978;72:495-7.

7 Teesdale $\mathrm{CH}$, Chitsulo L, Mkandawire AC. Concurrent dosage with niridazole and metrifonate for the treatment of bilharzia in schoolchildren in Malawi. Cent Afr $\mathcal{F}$ Med 1980;26:202-5.

8 Jordan P. Schistosomiasis: research to control. Am $\mathrm{f}$ Trop Med Hyg 1977;26:877-86.

9 Warren KS, Mahmoud AAF. Targeted mass treatment: a new approach to the control of schistosomiasis. Trans Assoc Am Physicians 1976;89 195-202.

10 McMahon JE. A note on drug trials in schistosomiasis. Trans $R$ Soc Trop Med Hyg $1981 ; 75: 597-8$.

11 Pugh RNH. A filtration method for schistosome egg quantification. Ann Trop Med Parasitol 1978;72:387-8.

12 Feldmeier H, Doehring E, Daffalla AA. Simultaneous use of a sensitive filtration technique and reagent strips in urinary schistosomiasis. Trans $R$ Soc Trop Med Hyg 1982;76:416-21.

${ }^{13}$ Pugh RNH, Bell DR, Gilles HM. Malumfashi endemic diseases research project. XV The potential medical importance of bilharzia in northern Nigeria; a suggested rapid, cheap and effective solution for control of Schistosoma haematobium infection. Ann Trop Med Parasitol 1980;74. 597-613.

14 Davis A, Bailey DR. Metrifonate in urinary schistosomiasis. Bull WHO $1969 ; 41: 209-24$.

(Accepted 26 November 1982)

\title{
Dietary sodium restriction for mild hypertension in general practice
}

\author{
G C M WATT, CATHERINE EDWARDS, J T HART, MARY HART, PAM WALTON, C J W FOY
}

\begin{abstract}
Eighteen patients with stable mild hypertension (mean blood pressure $144 / 93 \mathrm{~mm} \mathrm{Hg}$ ) restricted their sodium intake for eight weeks while taking part in a double blind randomised crossover trial of slow sodium and placebo tablets. Mean 24 hour urinary sodium excretion was 143 mmol(mEq) during the period on slow sodium and 87 mmol during the period on placebo. Five patients were unable to reduce their sodium intake below $120 \mathrm{mmol}$, but the others had a mean 24 hour urinary sodium excretion of $59 \mathrm{mmol}$ during the period on placebo. There was no significant difference in blood pressure between the slow sodium and placebo treatment periods, although the study had a power of $99 \%$ to detect a
\end{abstract}

Glyncorrwg Health Centre, West Glamorgan, SA13 3DP

G C M WATT, MB, MRCP, MRC research registrar (present address: head of WHO Monica Project, Glasgow Royal Infirmary, Glasgow G4 OSF)

CATHERINE EDWARDS, research assistant

J T HART, FRCGP, MRCP, general practitioner

MARY HART, MRC senior research assistan

PAM WALTON, MRC research assistant

MRC Epidemiology and Medical Care Unit, Northwick Park Hospital, Middlesex HA1 3UJ

C J W FOY, MSC, statistician (present address: Health Care Research Unit, University of Newcastle upon Tyne, Newcastle upon Tyne NE2 4AA) difference of $5 \mathrm{~mm} \mathrm{Hg}$ in mean arterial pressure between the two periods.

Moderate dietary sodium restriction does not lower blood pressure in patients with this degree of hypertension.

\section{Introduction}

Recent studies suggest that moderate dietary sodium restriction is effective in lowering blood pressure in hypertensive patients. ${ }^{12}$ These studies were based on patients referred to hospital and managed subsequently as inpatients or outpatients. We set out to establish whether dietary sodium restriction is also feasible and effective in the treatment of mild hypertension in general practice.

\section{Patients and methods}

Glyncorrwg is a relatively isolated former mining village in the South Wales valleys. About 1500 residents are registered with one general practitioner, along with about 600 other patients in neighbouring villages. Case finding for high blood pressure began in 1968-9, when $98 \%$ of adults aged $20-64$ had their blood pressure measured. Subsequently ascertainment, treatment, and follow up have been maintained more or less completely. ${ }^{3}$

Until mid-1981 the policy was to treat patients with hypotensive drugs when the mean of three consecutive readings exceeded 104 $\mathrm{mm} \mathrm{Hg}$ diastolic (phase $\mathrm{V}$ : reduced to $99 \mathrm{~mm} \mathrm{Hg}$ in 1981) or 179 
$\mathrm{mm} \mathrm{Hg}$ systolic, or both. People with pressures in the diastolic range 90-104 $\mathrm{mm} \mathrm{Hg}$ were reviewed yearly and treated only if warranted clinically. From 1968, 91 patients with diastolic pressures of 105 $\mathrm{mm} \mathrm{Hg}$ or over have begun treatment, as have 11 patients with pressures below this level. At any time about $90 \%$ of the adult population have had their blood pressure measured at least once during the previous five years. Virtually all blood pressure measurements were taken by two practice nurses using a random zero sphygmomanometer and all the data were recorded on computer file at the MRC Epidemiology and Medical Care Unit.

Patients were considered eligible for the study if their diastolic pressure lay in the range $90-104 \mathrm{~mm} \mathrm{Hg}$, taken as the mean of their six most recent blood pressure measurements at the health centre. Of the 51 patients who met this condition, one had recently died and another had moved away. Ten other patients were excluded because we hoped to include them in family studies of dietary sodium restriction. Twenty three of the remaining patients responded to an invitation to attend, with their spouses, a meeting in the local school hall, at which the risks and benefits of treating mild hypertension were explained. We also introduced the possible role of dietary sodium restriction as an alternative to drug treatment and described the design of a proposed trial of dietary sodium restriction. Twenty patients agreed to take part in the trial. This number was sufficient for the statistical requirements of the study, and no effort was made to recruit subjects from the 16 people who had not attended the meeting.

During a two week run in period all patients attended the health centre twice for baseline measurements of blood pressure, height, and weight. Two 24 hour urine specimens were collected for estimation of sodium and potassium intake and a blood sample taken for estimation of plasma renin activity. Dietary advice was also given at that stage.

The study consisted of a randomised double blind controlled trial of slow sodium and placebo tablets in patients who all restricted their sodium intake for eight weeks. Patients were allocated at random to four weeks of slow sodium tablets (Ciba, $10 \mathrm{mmol}(\mathrm{mEq})$ sodium per tablet) followed by four weeks of slow sodium placebo tablets (Ciba), or vice versa, with a fixed dose of eight tablets a day. The study design was explained carefully to each patient, but they did not know the number or timing of tablet changeovers.

Patients were asked not to add salt to their food, to use as little salt as possible in cooking, and to avoid salty foods. Each person was given a shopping guide, a list of local recipes adapted for low sodium cooking, and a wall poster indicating for each meal of the day which foods should be avoided, taken in moderation, or eaten freely. Low sodium bread baked with half its usual salt content was ordered from a local baker and salt free butter was imported from a nearby town. Both items were sold to patients at cost price. Low sodium baking powder and gravy browning were provided free of charge. No attempt was made to influence potassium or energy intake. Before the trial each person kept a simple seven day food diary, which provided a basis for individual dietary advice. Halfway through the study there was a meeting of all participants to discuss their experience of sodium restriction.

Blood pressure and weight were measured at weekly afternoon clinics at the health centre. Each patient was seen on the same day of the week at the same time of day. All blood pressure measurements were taken by two experienced MRC fieldworkers, who took the same number of readings from each patient during each period of the trial. Blood pressure was measured in the left arm using a random zero sphygmomanometer with the patient seated for five minutes beforehand. Large cuffs were used for obese arms and diastolic pressures read at phase V. Patients started a 24 hour urine collection with the second void on the day of their attendance at the clinic, and completed it with the first void the next day.

Blood samples were taken for estimation of plasma renin activity at the end of the third clinic attendance in each period. Blood was taken without stasis with the patient supine for three minutes beforehand. Plasma was separated within 15 minutes, stored in a freezer, and transported later for analysis at St Mary's Hospital Medical School, London.

None of the 18 patients who completed the study was receiving hypotensive medication or any drug that might interfere with sodium balance. One patient had had a retinal artery thrombosis but the others were free of clinical cardiovascular, cerebrovascular, and renal disease. There were six men and 12 women with an average age of 52 years (range 31-64). Mean blood pressure was $144.4 \mathrm{~mm} \mathrm{Hg}$ systolic (range 128-164) and $92.9 \mathrm{~mm} \mathrm{Hg}$ diastolic (range 90-100), based on six measurements taken over an average of $5 \cdot 2$ years (range 1-12).

Two patients (one in each randomised group) dropped out early in the study owing to difficulty in complying with the diet: results are therefore presented for the remaining 18 patients and are based on all the data collected during each period of the trial unless stated otherwise.

The statistical methods for design and analysis followed closely those given in two recent reviews of the crossover clinical trial. ${ }^{45}$ Using published data ${ }^{6}$ on the within-person variability of blood pressure, we designed the study so that it had a $90 \%$ power to detect a difference of $3 \mathrm{~mm} \mathrm{Hg}$ in mean arterial pressure (diastolic plus one third pulse pressure) in a two sided test at the $5 \%$ level: consequently it had a power of $99 \%$ to detect a difference of $5 \mathrm{~mm} \mathrm{Hg}$.

Estimates of the mean differences in blood pressure and other variables between the first and second four week periods, and between the periods on slow sodium and placebo tablets, were obtained after ensuring that there was no interaction between these effects (which would invalidate the remaining differences unless adequately explained). With equal numbers in each randomised group the two effects were estimated independently: their significance was evaluated by paired $t$ tests.

\section{Results}

\section{ORDER EFFECTS}

Mean blood pressure fell significantly from $149 \cdot 9 / 91.3 \mathrm{~mm} \mathrm{Hg}$ during the run in period to $137 \cdot 2 / 83.3 \mathrm{~mm} \mathrm{Hg}$ during the first four weeks of the trial, and fell again slightly to $135.3 / 81.5 \mathrm{~mm} \mathrm{Hg}$ during the second four weeks (table I). There were no significant differences in blood pressure, body weight, or 24 hour urinary electrolyte excretion between the first and second four weeks of the trial.

TABLE I-Randomised controlled trial of dietary sodium restriction:order effects. Values are means. (Number of subjects $=18$ )

\begin{tabular}{|c|c|c|c|}
\hline & \multirow{2}{*}{$\begin{array}{l}\text { Baseline } \\
\text { measurements } \\
(2 \text { weeks' } \\
\text { run in })\end{array}$} & \multicolumn{2}{|c|}{ Trial measurements } \\
\hline & & $\begin{array}{c}\text { First } \\
4 \text { weeks }\end{array}$ & $\begin{array}{l}\text { Second } \\
4 \text { weeks }\end{array}$ \\
\hline $\begin{array}{l}\text { Systolic pressure }(\mathrm{mm} \mathrm{Hg}) \\
\text { Diastolic pressure }(\mathrm{mm} \mathrm{Hg}) \\
\text { Mean arterial pressure }(\mathrm{mm} \mathrm{Hg}) \\
\text { Weight }(\mathrm{kg}) \\
24 \mathrm{~h} \text { Urinary sodium excretion }(\mathrm{mmol}) \\
24 \text { h Urinary potassium excretion }(\mathrm{mmol}) \\
\text { Plasma renin activity }(\mathrm{ng} / \mathrm{l} / \mathrm{h})\end{array}$ & $\begin{array}{r}149 \cdot 9 \\
91 \cdot 3 \\
110 \cdot 8 \\
77 \cdot 9 \\
158 \cdot 6 \\
59 \cdot 2 \\
1226\end{array}$ & $\begin{array}{r}137 \cdot 2 \\
83 \cdot 3 \\
101 \cdot 3 \\
77 \cdot 4 \\
108 \cdot 5 \\
54 \cdot 1 \\
1890\end{array}$ & $\begin{array}{r}135 \cdot 3 \\
81 \cdot 5 \\
99 \cdot 4 \\
77 \cdot 3 \\
121 \cdot 5 \\
50 \cdot 5 \\
2358\end{array}$ \\
\hline
\end{tabular}

Conversion: $S I$ to traditional units-Sodium: $1 \mathrm{mmol}=1 \mathrm{mEq}$. Potassium: $1 \mathrm{mmol}=1 \mathrm{mEq}$.

\section{TREATMENT EFFECTS}

Mean 24 hour urinary sodium excretion was $159 \mathrm{mmol}(\mathrm{mEq})$ during the run in period, $87 \mathrm{mmol}$ during the period on placebo, and 143 mmol during the period on slow sodium (tables I and II). Figure 1 shows the mean sodium excretion for each patient in each period of the study, based on four single weekly 24 hour urine collections. Five patients did not manage to reduce their sodium intake below 120 mmol a day during the period on placebo, and three of these were also thought to have been non-compliant with the tablets, as their sodium intake was similar during the two periods (in two cases it was actually less during the period on slow sodium). The remaining 13 patients had a mean 24 hour urinary sodium excretion of $149 \mathrm{mmol}$ during the run in period, $59 \mathrm{mmol}$ during the period on placebo, and $139 \mathrm{mmol}$ during the period on slow sodium (tables I, II). There were no significant differences in potassium intake throughout the study. Table II shows the mean blood pressure, body weight, 24 hour urinary electrolyte excretion, and plasma renin activity during the periods on slow sodium and placebo both for the whole group and for the 13 patients who achieved a satisfactory reduction in sodium intake. Only the differences in sodium excretion and plasma renin activity were statistically significant. Figure 2 shows the mean arterial pressure for each patient in each period of the trial, based on four weekly duplicate measurements.

No difference was found between blood pressure measured during the fourth week of placebo compared with the fourth week of slow sodium. These findings applied equally to patients receiving slow sodium during the first and second periods of the trial. 


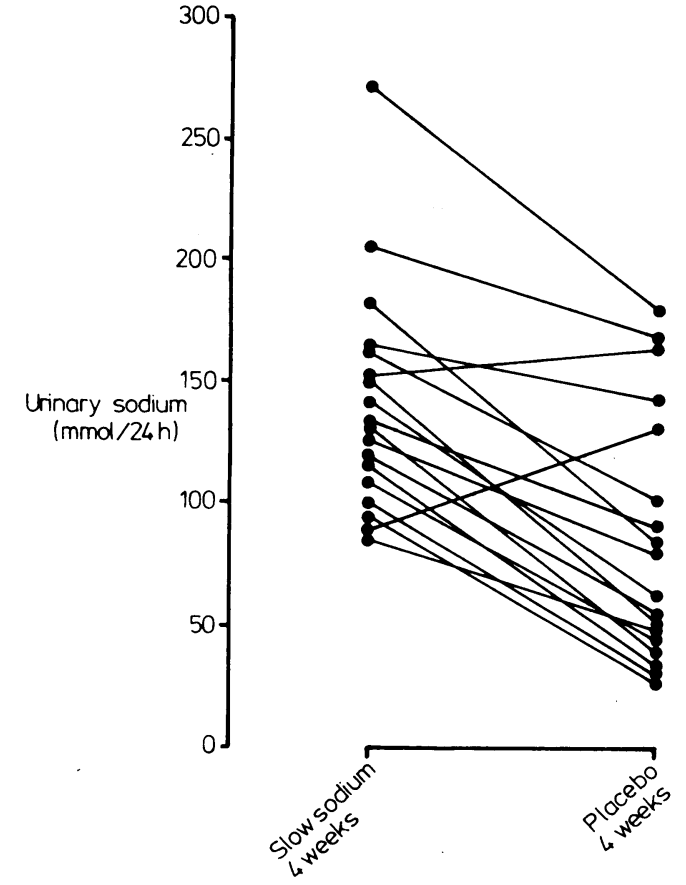

FIG 1-Individual changes in 24 hour urinary sodium excretion $(\mathrm{n}=18)$. ( $1 \mathrm{mmol}$ sodium $/ 24 \mathrm{~h}=1 \mathrm{mEq}$ sodium $/$ 24 h.) in general practice. For example, Kawasaki et $a l^{18}$ and Van Brummelen et al ${ }^{19}$ admitted their patients to hospital where they could administer low sodium diets of 9 and $50 \mathrm{mmol}$ a day, respectively. These studies provide no guide to the effect and feasibility of achieving these levels of intake in free living subjects.

Parijs et $a l^{20}$ studied patients with an initial mean diastolic pressure of $115 \mathrm{~mm} \mathrm{Hg}$, and though blood pressure fell by $7 \cdot 7 / 4.4 \mathrm{~mm} \mathrm{Hg}$ when sodium intake was reduced from 191 to $93 \mathrm{mmol}$ daily, this finding may not apply to patients with mild hypertension.

Morgan $e t$ al $^{21}$ reported a reduction in pressure in patients who reduced their sodium intake from $195 \mathrm{mmol}$ to $157 \mathrm{mmol}$ a day, but the evidence for this reduction in sodium intake was based on an unequal number of 24 hour urine collections from each patient, and one third of the patients provided no initial urine specimen.

MacGregor et $a l^{2}$ admitted patients to their study if diastolic pressure lay in the range $90-109 \mathrm{~mm} \mathrm{Hg}$ after two months of observation. As mean diastolic pressure was $98 \mathrm{~mm} \mathrm{Hg}$, probably many of their patients had pressures high enough at the outset to justify drug treatment. Their data were also based on supine recordings. General practitioners do not as a rule measure blood pressure in this position, and it is not clear how these pressures relate to observations made in general practice. It cannot be assumed that supine pressures are comparable with sitting pressures, as standing pressures were on average $9 \mathrm{~mm} \mathrm{Hg}$ higher than supine pressures throughout this study.

In view of this uncertainty we set out to study the feasibility

TABLE II-Randomised controlled trial of dietary sodium restriction: effects of changes in sodium intake. Values are means

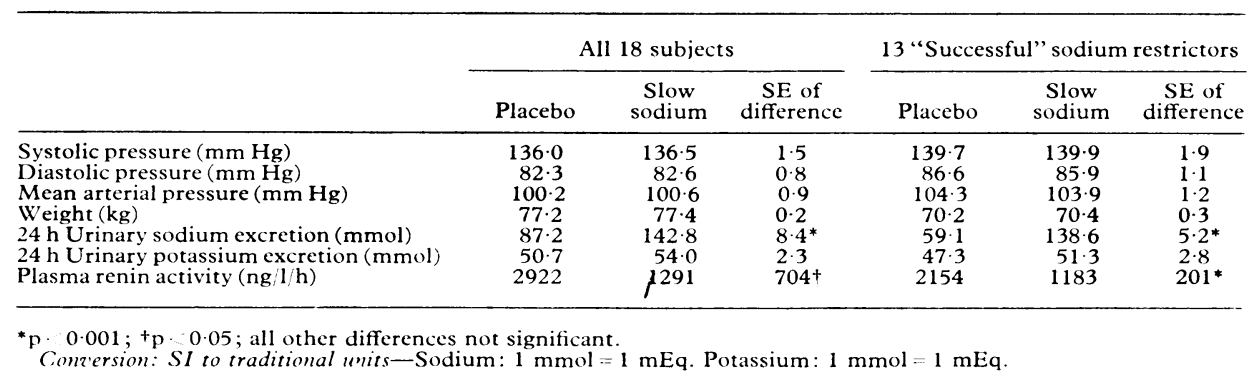

\section{Discussion}

Current clinical practice is to begin hypotensive medication when diastolic pressures are sustained at $100 \mathrm{~mm} \mathrm{Hg}$ or over. The value of drug treatment in patients with pressures in the range $90-99 \mathrm{~mm} \mathrm{Hg}$ is not yet established, ${ }^{8}$ and evidence is awaited from the MRC Mild Hypertension Trial. ${ }^{9}$ With increasing awareness of adverse reactions to common hypotensive drugs ${ }^{10-12}$ there is doubt about drug treatment as the first line measure in managing mild hypertension ${ }^{13} 14$ and great interest in methods of lowering blood pressure without drugs. ${ }^{15}$

Extreme dietary sodium restriction down to $10 \mathrm{mmol}$ a day does reduce blood pressure in severe hypertension, ${ }^{1617}$ but this monotonous and unpalatable diet has no place in the management of large numbers of free living, healthy people. The key question is whether lesser degrees of sodium restriction are also effective in lowering pressure. Reviewing four controlled clinical trials of dietary sodium restriction, ${ }^{18-11}$ Amery et al concluded that blood pressure would fall by $11 \mathrm{~mm} \mathrm{Hg}$ systolic and $10 \mathrm{~mm} \mathrm{Hg}$ diastolic if sodium intake could be reduced from $200 \mathrm{mmol}$ to $100 \mathrm{mmol}$ daily. This opinion was supported by MacGregor et al, ${ }^{2}$ who found that mean arterial pressure fell by $7 \cdot 1 \mathrm{~mm} \mathrm{Hg}$ when sodium intake was changed from 162 to 86 $\mathrm{mmol}$ daily. There are several problems, however, in relating the results of the studies to the management of mild hypertension

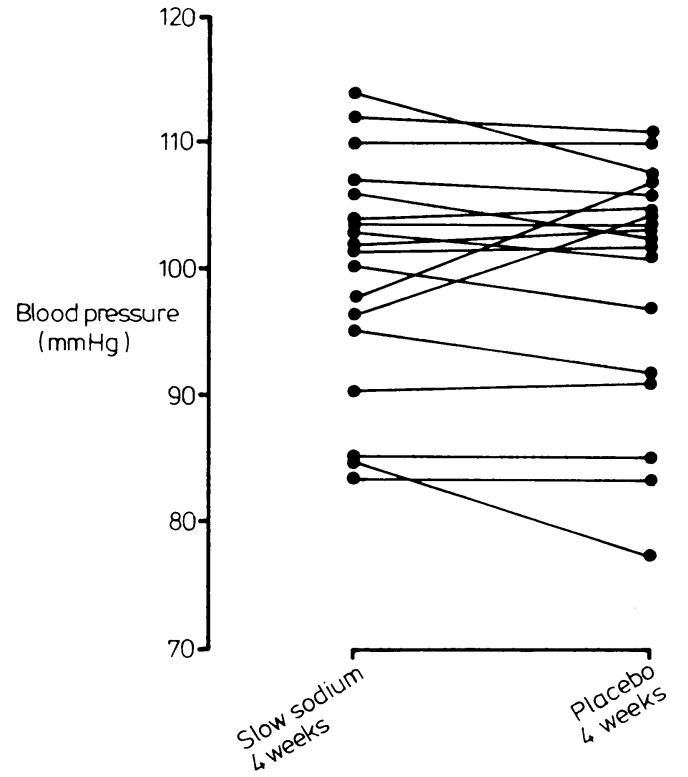

FIG 2-Individual changes in mean blood pressure (diastolic pressure plus one third of pulse pressure $)(n=18)$. 
and effectiveness of moderate sodium restriction in the treatment of patients with mild hypertension in general practice.

We used the study design proposed by Parijs et al:" in 1973 and first implemented by MacGregor et al, ${ }^{2}$ in which all patients restrict their sodium intake while taking either slow sodium or placebo tablets. The principal advantage of this design is that treatment and control groups are managed in an identical way, and the results can therefore be interpreted solely on the basis of changes in sodium intake.

Patients were eligible for the study if diastolic pressure lay in the range $90-104 \mathrm{~mm} \mathrm{Hg}$, taken as the mean of six casual measurements, this number of readings having been chosen in an attempt to exclude patients with only transiently raised pressure. The 18 patients who completed the study had an initial mean diastolic pressure of $92.9 \mathrm{~mm} \mathrm{Hg}$, compared with $93.3 \mathrm{~mm} \mathrm{Hg}$ in the 33 patients who were also eligible but did not take part. We consider therefore that the patients in this study were representative of patients with stable mild hypertension, with the reservation that the practice policy of treating all diastolic pressures at or above $105 \mathrm{~mm} \mathrm{Hg}$ (mean of three readings) over more than 10 years will have systematically culled those with casual pressures at the upper end of the diastolic range $90-104 \mathrm{~mm} \mathrm{Hg}$.

The relatively low mean pressure of these patients may also be explained by two other factors. Firstly, the distribution of pressure in the range $90-104 \mathrm{~mm} \mathrm{Hg}$ is weighted towards lower pressures. Secondly, the mean of six pressures must take into account the tendency of blood pressure to fall with repeated measurement. ${ }^{2:}$ Based on only the three highest consecutive pressures of the six used to classify patients for this study, mean diastolic pressure was $96.9 \mathrm{~mm} \mathrm{Hg}$.

The study achieved its main aim of comparing blood pressure at two levels of sodium intake in patients with mild hypertension. Not all patients were willing or able to restrict their sodium intake, and some were also non-compliant with the tablets. Two patients (fig 1) actually had higher sodium excretion during the period on placebo and were thought not to have taken any of the tablets despite continuing to attend the weekly clinics. In general these results show that substantial reductions in sodium intake are feasible in general practice with willing patients given appropriate advice and support. Studies in which all subjects achieve low sodium intakes are probably not representative of the general population.

Compared with baseline measurements blood pressure fell in all patients during the study, irrespective of whether they were taking slow sodium or placebo tablets. The fall of $10 \mathrm{~mm} \mathrm{Hg}$ in diastolic pressure is most likely explained by diminution of the alerting response and a small reduction in body weight.

There was no significant difference in mean arterial pressure between the periods on slow sodium and placebo tablets, despite a difference of $56 \mathrm{mmol}$ in 24 hour urinary sodium excretion and a twofold difference in plasma renin activity. In contrast, in a virtually identical study MacGregor et al ${ }^{2}$ observed a fall of $7 \cdot 1 \mathrm{~mm} \mathrm{Hg}$ in mean arterial pressure between the fourth week of slow sodium and the fourth week of placebo, in association with a fall of $76 \mathrm{mmol}$ in 24 hour urinary sodium excretion and a similar difference in plasma renin activity. Making this comparison in the 13 patients who reduced their sodium intake satisfactorily in our study, we found no significant difference in mean arterial pressure despite a fall of $57 \mathrm{mmol}$ in sodium excretion: the $95^{\circ}$, confidence interval extended from a rise of $3.0 \mathrm{~mm} \mathrm{Hg}$ to a fall of $5.4 \mathrm{~mm} \mathrm{Hg}$.

The difference in urinary sodium excretion during the periods on slow sodium in the two studies $(162 v 142 \mathrm{mmol})$ was insufficient to account for the difference in blood pressure findings. There were more men and a greater racial mix in the study by MacGregor et $a l,,^{2}$ and these differences may be important. The studies were not large enough to investigate differences between men and women and between blacks and whites.

Arguably our study did not last long enough to detect an effect of sodium restriction on patients with only mildly raised pressures. For example, Morgan et al ${ }^{21}$ found that blood pressure fell only marginally during the first six months of their study, and the maximum fall did not occur until 18 months. Nevertheless, the evidence that the fall in blood pressure in their study was accompanied by a reduction in sodium intake was unsatisfactory (see above). Most studies reporting an effect of sodium restriction on blood pressure have observed this effect within 28 days, and usually much sooner.

The major difference between these two studies which might explain their different results is the level of initial blood pressure in the two groups of patients. Together the results of the two studies are consistent with the suggestion that the effect of sodium restriction on blood pressure is related directly to the level of the initial blood pressure, in agreement with uncontrolled observations. ${ }^{23}$

\section{Conclusion}

Our study provides no evidence that moderate dietary sodium restriction lowers the blood pressure in patients with mild hypertension in the general population. Evidence from other studies is consistent with a hypotensive effect in patients with higher pressures, who would normally be treated with drugs. Sodium restriction may reduce drug requirements, ${ }^{24}$ but it is not clear whether the effect of a low sodium diet alone is large enough to provide adequate control of blood pressure in these patients. Even in the most convincing study of the effect of sodium restriction ${ }^{2}$ blood pressure stayed the same, or rose, during the period of low sodium diet in one third of the patients. Larger studies are required to determine the effect of sodium restriction on patients with different levels of blood pressure, and to identify factors which may indicate susceptibility to sodium restriction.

This work was supported by the British Heart Foundation. We thank Dr Robin Elsdon-Dew (Ciba, Horsham) for supplies of slow sodium and placebo tablets; Dr David Gordon, of St Mary's Hospital Medical School, London, for estimations of plasma renin activity, Dr Tony Ames and Mr Tony Thomas, of Neath General Hospital, West Glamorgan, for urine analyses; and Dr Tom Meade for comments on an earlier draft of this paper. Catherine Edwards is supported by grant $81 / 37$ from the British Heart Foundation.

Requests for reprints should be sent to Dr G C M Watt.

\section{References}

' Amery A, Bulpitt C, Fagard R, Staessen J. Does diet matter in hypertension? Eur Heart $\mathcal{F} 1980 ; 1: 299-308$

2 MacGregor GA, Markandu ND, Best FE, et al. Double-blind randomised crossover trial of moderate sodium restriction in essential hypertension. Lancet $1982 ; \mathrm{i}: 351-4$

${ }^{3}$ Hart JT. Hypertension. London: Churchill Livingstone, 1980.

${ }^{4}$ Hills M, Armitage P. The two-period cross-over clinical trial. Br $\mathcal{F}$ Clin Pharmacol 1979;8:7-20.

${ }^{5}$ Barker N, Hews RJ, Huitson A, Poloniecki J. The two period crossover trial. Bulletin in Applied Statistics 1982;9:67-116.

${ }^{6}$ Armitage P, Fox W, Rose GA, Tinker CM. The variability of measurements of casual blood pressure. II. Survey experience. Clin $S_{c i} 1966$; 30:337-44

Australian National Blood Pressure Study Management Committee. The Australian therapeutic trial in mild hypertension. Lancet $1980 ; \mathrm{i}: 1261-7$.

* WHO/ISH Mild Hypertension Liaison Committee. Trials of the treatment of mild hypertension. An interim analysis. Lancet 1982;i:149-56.

${ }^{9}$ Medical Research Council Working Party on Mild to Moderate Hypertension. Randomised controlled trial of treatment for mild hypertension: design and pilot trial. Br Med $\mathcal{F} 1977 ; ;: 1437-40$.

10 Medical Research Council Working Party on Mild to Moderate Hypertension. Adverse reactions to bendrofluazide and propranolol for the treatment of mild hypertension. Lancet 1981 ;ii:539-43.

1 Anonymous. Possible dangers of the label hypertension. Lancet $1982 ; \mathrm{i}$ : $547-8$

12 Jachuck SJ, Brierley H, Jachuck S, Willcox PM. The effect of hypotensive drugs on the quality of life. $\mathcal{F} R$ Coll Gen Pract 1982;32:103-5.

${ }^{13}$ Oliver MF. Risks of correcting the risks of coronary disease and stroke with drugs. N Engl 7 Med $1982 ; 306: 297-8$.

14 Dollery CT. Does it matter how blood pressure is reduced? Clin Sct $1981 ; 61: 413 \mathrm{~s}-20 \mathrm{~s}$ 
15 Anonymous. Lowering blood pressure without drugs. Lancet 1980;ii: 459-61.

16 Kempner $W$. Treatment of hypertensive vascular disease with rice diet. Am $\mathcal{F}$ Med 1948;4:545-77.

17 Medical Research Council. The rice diet in the treatment of hypertension. Lancet 1950 ;ii:509-13.

${ }^{18}$ Kawasaki T, Delea CS, Bartter FC, Smith H. The effect of high-sodium and low-sodium intakes on blood pressure and other related variables in human subjects with idiopathic hypertension. Am $\mathcal{F}$ Med 1978;64: 193-8.

19 Van Brummelen P, Schalekamp M, De Graeff J. Influence of sodium intake on hydrochlorothiazide-induced changes in blood pressure, serum electrolytes, renin and aldosterone in essential hypertension. Acta Med Scand 1978;204:151-7.
${ }^{20}$ Parijs J, Joossens JV, van der Linden L, Verstreken G, Amery AKPC. Moderate sodium restriction and diuretics in the treatment of hypertension. Am Heart $\mathcal{f} 1973 ; 85: 22-34$.

${ }^{21}$ Morgan T, Adam W, Gillies A, Wilson M, Morgan G, Carney S. Hypertension treated by salt restriction. Lancet 1978;i:227-30.

${ }^{22}$ Beevers DG. Blood pressures that fall on rechecking. $\mathrm{Br}$ Med $\mathcal{f} 1982$; 284:71.

${ }^{23}$ Parfrey PS, Markandu ND, Roulston JE, Jones BE, Jones JC, MacGregor GA. Relation between arterial pressure, dietary sodium intake and renin system in essential hypertension. Br Med F $1981 ; 283: 94-7$.

24 Beard TC, Cooke HM, Gray WR, Barge R. Randomised controlled trial of a no-added-sodium diet for mild hypertension. Lancet 1982 ;ii :455-8.

(Accepted 29 November 1982)

\title{
Method of healing diabetic forefoot ulcers
}

\author{
J P POLLARD， L P LE QUESNE
}

\begin{abstract}
Six diabetic patients with neuropathic ulceration of the sole of the foot (seven feet, eight ulcers) were treated by the application of a below knee walking plaster with a rubber rocker. All the ulcers healed with this treatment, greatly reducing the usual period of hospital inpatient stay. After healing, study of the forces acting on the sole of the foot showed that these ulcers occur at the site of maximal horizontal shear force and confirmed that they occur at the site of maximal vertical force.

This treatment is highly effective for neuropathic ulcers of the sole not affecting bone or complicated by deep sepsis. There may be a high rate of recurrence, however, reflecting inadequacy of methods of protecting damaged neuropathic feet.
\end{abstract}

\section{Introduction}

It has long been thought that mechanical factors play a part in diabetic neuropathic ulcers of the sole. A recent study ${ }^{1}$ showed clearly that these ulcers occur at the site of maximum pressure (vertical force), and although there are certainly other factors in their formation, the site of the ulcer is clearly determined by mechanical factors.

We have shown that both the vertical and shearing (longitudinal and transverse) components of force acting on the foot during walking are greatly modified by the type of footwear, and in particular that a below knee plaster cast with a rubber rocker greatly reduces all three components of force. ${ }^{2}$ This suggested that it might be possible to heal diabetic neuropathic ulcers in such a cast, and we therefore report the results of this method of treatment. We also give the results of measuring the components of force after the ulcers had been healed.

Middlesex Hospital, London W1N 8AA

J P POLLARD, FRCS, research assistant (now consultant orthopaedic surgeon, Horton Hospital, Banbury)

L P LE QUESNE, DM, FRCS, professor, department of surgical studies

\section{Method}

TREATMENT OF ULCERS

For treatment in a plaster cast the ulcer had to be moderately clean with healthy granulation tissue and without excessive discharge. We achieved this by bed rest, paring the overhanging edges of the ulcer, and on occasions antibiotics for a short period. Deep sepsis or osteomyelitis of the metatarsal head rendered the ulcer unsuitable for treatment by this method.

A conventional below knee plaster cast with a rubber rocker for weight bearing was then applied. On account of the sensory peripheral neuropathy great care was taken to apply adequate padding, and an extra layer of self adhesive foam rubber was applied around the malleoli. The forward projection of the cast was restricted to the level of the mid-shaft of the proximal phalanges of the toes, so that by dorsiflexion of the toes the dressing could be withdrawn, the ulcer inspected, and a new dressing inserted. Re-dressing was usually required daily, the dressing used being non-adhesive, presterilised Melolin (Smith and Nephew Ltd). The plaster was retained for two weeks after healing to allow some consolidation to occur.

In practice the plaster casts required changing after three or four weeks because of softening or soiling from discharge, or to allay anxiety about the state of the neuropathic foot in a plaster cast; however, no troublesome pressure problems were encountered.

\section{ANALYSIS OF FORCES}

Once the ulcer was healed it was possible to analyse the forces under the forefoot, as described. ${ }^{2} 3$ The three components of force (vertical, longitudinal shear, transverse shear) were analysed separately in different footwear using transducers attached to the sole of the foot with double sided adhesive tape. Transducers were located under the hallux, under the first, second and third, and fourth and fifth metatarsal heads, and under the midpoint of the heel.

Recordings were made with the patients walking barefoot, in a pair of conventional leather shoes, in the same shoes with a single $6 \mathrm{~mm}$ layer of low density Plastazote as an insole, in a pair of extra lepth surgical shoes (Drushoe) designed to accommodate two $6 \mathrm{~mm}$ layers of Plastazote (one of medium density, one of low density), and in a below knee plaster cast.

\section{PATIENTS}

Seven ulcerated feet in six diabetic patients (age range 27-75 years; mean 47 ) were treated by the methods described. All patients had severe peripheral neuropathy affecting the legs with absent or severely impaired sensation to light touch and pain. In all except one patient both peripheral pulses were palpable at the ankle; in the oldest patient 